\title{
Voluntary and automatic attentional control of visual working memory
}

\author{
BRANDON K. SCHMIDT, EDWARD K. VOGEL, GEOFFREY F. WOODMAN, and STEVEN J. LUCK \\ University of Iowa, Iowa City, Iowa
}

\begin{abstract}
Previous studies of attention-directing cues have focused largely on the effects of cuing on perceptual processes, but cuing may also influence the transfer of perceptual representations into visual working memory. In the present study, we examined this potential role of cues, using both predictive and nonpredictive cues in the context of a visual working memory task. Each trial began with a cue, followed by an array of six colored squares, a delay interval, and then a probe square presented at the location of one of the squares in the previous array. The subjects were required to indicate whether the color of the probe square was the same as the color of the square that had previously been presented at the same location. Performance on this working memory task was more accurate when the cued location was probed than when an uncued location was probed, even when the cued location was no more likely to be probed than any of the uncued locations. An additional experiment using the abrupt-onset paradigm of Yantis and Jonides (1984) yielded similar results. Thus, visual transients may automatically influence the transfer of perceptual representations into visual working memory.
\end{abstract}

Many previous studies have shown that stimuli presented within attended regions of space are processed more rapidly and more accurately than those presented in unattended regions (e.g., Cheal \& Gregory, 1997; Henderson, 1996; Posner, 1980; Prinzmetal, Presti, \& Posner, 1986), and the purpose of the present study is to explore the nature of attention-related increases in processing efficiency. Specifically, we examine the possibility that attended-location objects receive priority for entry into visual working memory. Although many theories of attention have proposed that spatial attention has this effect (e.g., Bundesen, 1990; Duncan \& Humphreys, 1989), there has been relatively little direct empirical investigation of this proposal.

To explore the role of spatial attention in controlling access to visual working memory, we used a cuing paradigm in which a white square appeared at a peripheral location, directing the observers' attention to this location (see Figure 1). Performance on a visual working memory task was then measured for stimuli appearing at the cued location on some trials (valid trials) and for stimuli appearing at an uncued location on others (invalid trials). Most previous studies of cuing have assumed that cues influence the allocation of perceptual processing resources (Posner, 1980) or bias decision processes (Lappin \& Uttal, 1976; Shiu \& Pashler, 1994). In the present study, we examined the role of spatial cues in controlling the transfer of attended-

This study was supported by grants from the National Institute of Mental Health (MH56877 and MH63001), the National Science Foundation (SBR 98-09126), and the Human Frontier Science Program (RG0136). Correspondence concerning this article should be addressed to S. J. Luck, Department of Psychology, University of Iowa, 11 Seashore Hall E, Iowa City, IA 52242-1407 (e-mail: steven-luck@uiowa.edu). location perceptual representations into visual working memory. In particular, we examined whether sudden-onset cues automatically influence visual working memory, so that cued items are more likely to be remembered than uncued items, even when the cues do not predict which item will be tested. Previous studies have shown that sudden onsets may influence perceptual performance (Hopfinger \& Mangun, 1998; Jonides, 1981; Luck \& Thomas, 1999; for a review, see Yantis, 1996), but no one has examined whether sudden-onset cues automatically influence visual working memory.

The role of attention in working memory was addressed many years ago by the classic iconic memory studies of Sperling (1960) and Averbach and Coriel (1961). In these studies, subjects were presented with a brief array of alphanumeric characters and were required either to report all of the characters (whole report) or to report a subset of the characters that were indicated with a cue (partial report). The cue was either a tone that indicated which row of characters to report (Sperling, 1960) or a bar or circle that indicated which individual character to report (Averbach \& Coriel, 1961). In the whole-report conditions, recall of the items was accurate for arrays of $4-5$ characters and declined as the number of items in the arrays increased. In the partial-report conditions, performance was highly accurate even for very large arrays, as long as the number of cued items did not exceed the capacity of working memory. Thus, observers were apparently able to selectively transfer the cued characters into working memory (for more recent studies of this nature, see Gegenfurtner \& Sperling, 1993; Irwin \& Gordon, 1998).

The main goal of these previous studies was to demonstrate that the partial-report advantage would be present even when the cue appeared after the offset of the charac- 


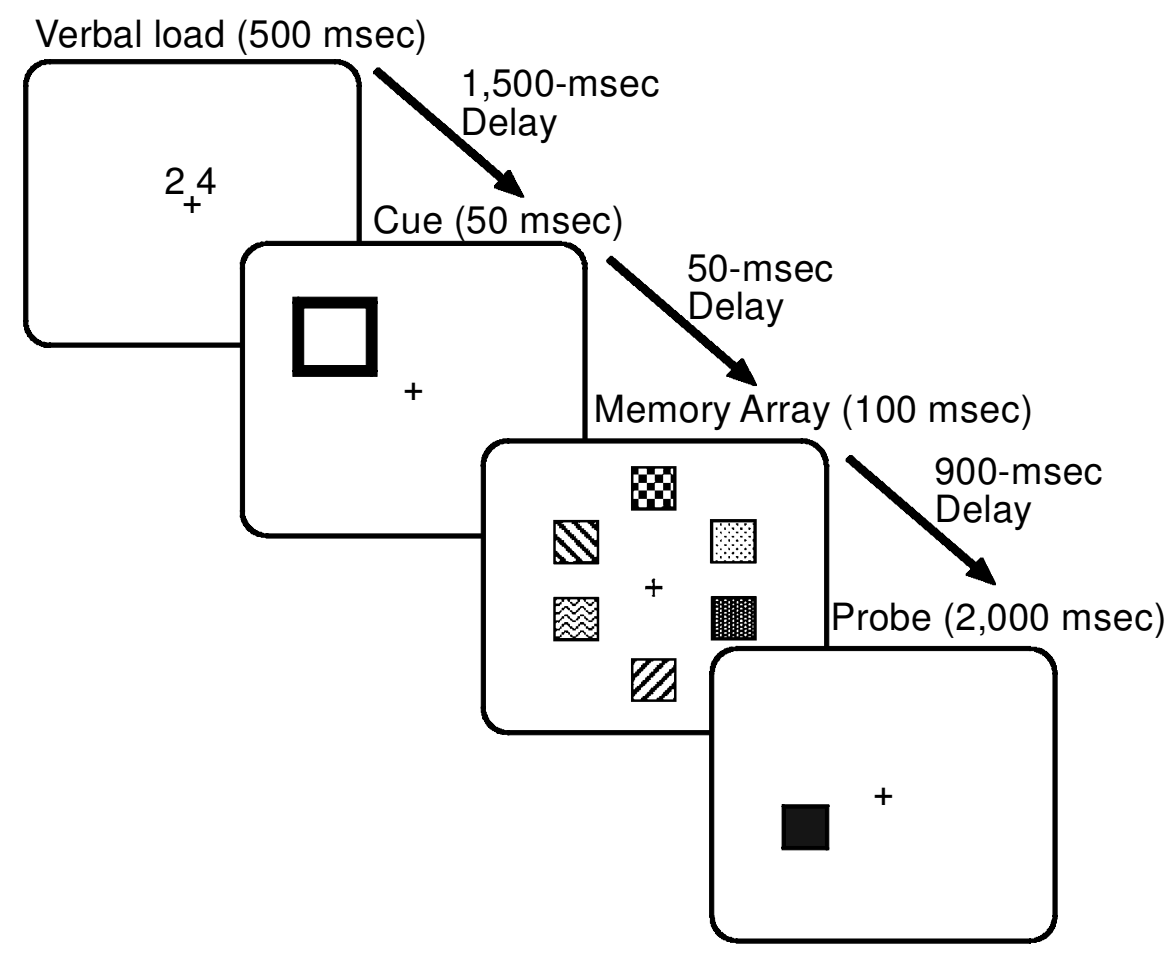

Figure 1. Example of the procedure used in Experiment 1. Note that, for illustrative purposes, the stimuli are drawn much larger than they appeared on the actual video display. Note also that different fill patterns are used to represent different colors and that the verbal load, cue, and fixation point were presented in white on a gray background.

ter array, consistent with the presence of a high-capacity but short-lived sensory memory system. For the purposes of the present study, however, the most relevant result is the simple finding that cues can be used to control the transfer of information into working memory.

More recently, it has become clear that there are separate verbal and visual short-term memory systems (for reviews, see Baddeley, 1986; Logie, 1995). Sperling (1960) and Averbach and Coriel (1961) used stimuli that could easily be converted into a verbal code, and the subjects responded by reporting the names of the stimuli verbally. It is, therefore, very likely that the cues in these studies influenced the transfer of information into verbal working memory, rather than into visual working memory. To isolate the role of attention in controlling the visual component of working memory, some previous studies have used stimuli, such as lines of varying lengths, that are not nameable as easily as letters and digits (see, e.g., Palmer, 1988, 1990; Scott-Brown \& Orbach, 1998). These studies have provided evidence that attention does indeed control the transfer of perceptual representations into the visual component of working memory.

However, it is difficult to be certain that subjects do not create their own verbal labels for these stimuli during an experiment. Palmer and Ames (1992) addressed this possibility by using nine different line lengths, making it difficult for subjects to form categorical (and therefore ver- bal) representations of the stimuli. The present study used a different strategy, requiring subjects to perform a concurrent articulatory suppression task that inhibited the verbal recoding of visual stimuli. Specifically, the subjects were presented with two digits at the beginning of each trial, and they were required to repeat these digits aloud throughout the course of each trial. A large number of studies have demonstrated that this procedure dramatically impairs the recoding of visual information into verbal form (see, e.g., Besner, Davies, \& Daniels, 1981; Estes, 1973; Levy, 1971; Murray, 1967). Thus, the present study was designed to provide converging evidence for the proposal that attention influences the visual component of working memory.

The present study also explores the possibility that the capture of attention by sudden-onset stimuli leads to changes in working memory, as well as in perception. Previous studies have shown that targets that are immediately preceded by a visual transient at a nearby location are detected more quickly and discriminated more accurately than targets that are preceded by a transient at a distant location, even if the transient is not predictive of the target location (e.g., Jonides, 1981; Luck \& Thomas, 1999; Posner $\&$ Cohen, 1984). Similarly, Yantis and Jonides (1984) used a modified visual search paradigm to show that suddenonset objects are searched before objects that are revealed by the offset of camouflage, suggesting that they automat- 
ically capture attention. There is some debate about the extent to which the capture of attention by sudden-onset stimuli is fully automatic (see, e.g., Folk, Remington, \& Johnston, 1993; Yantis, 1993). For example, Folk and his colleagues (e.g., Folk \& Remington, 1999; Folk, Remington, \& Johnston, 1992; Folk, Remington, \& Wright, 1994) found that the capture of attention by onsets could be eliminated by requiring subjects to search for stimuli that were not defined by onsets (for contrary findings, however, see Luck \& Thomas, 1999; Theeuwes, Kramer, \& Atchley, 1999). In addition, sudden onsets may fail to capture attention if attention is already strongly focused elsewhere (Yantis \& Jonides, 1990). However, it is clear that sudden onsets can be quite powerful attractors of attention, even if they are not always able to override voluntary attentional control (for a review, see Yantis, 1996).

Almost all previous studies of automatic attention capture by sudden onsets have focused on reaction time measures, implicitly or explicitly assuming that faster reaction times reflect greater perceptual efficiency. In a few studies, the accuracy of unspeeded responses has been examined, and it has been concluded that sudden onsets lead to changes in perceptual processing (Henderson \& Macquistan, 1993; Luck \& Thomas, 1999). However, to our knowledge, no one has ever addressed the possibility that sudden onsets may also influence the transfer of perceptual representations into visual working memory, and that is the primary goal of this study.

\section{EXPERIMENT 1}

This experiment combined a cuing paradigm with a visual working memory paradigm. As is illustrated in Figure 1 , each trial began with the presentation of a cue at one of six locations. This was followed by a memory array consisting of six colored squares, one at each of the six locations. After a brief delay, a single probe square appeared at one of these locations, and the subjects were required to report whether the color of this item was the same as the color of the square that had appeared at that location in the preceding memory array. Thus, to perform the task accurately, the subjects had to store the colors of the memory array items in visual working memory.

We have previously shown that an array of six highly discriminable colors can easily be perceived but exceeds the capacity of visual working memory (Luck \& Vogel, 1997; Vogel, Woodman, \& Luck, 2001). Thus, performance of the present task was not limited by perceptual quality. In addition, the responses were made without time pressure, and the use of a single probe square obviated the need to make a separate same-different decision for each square in the memory array. Consequently, performance in this task was limited largely by visual working memory and was not significantly limited by perceptual, decision, or motor processes.

For one group of subjects, the cue correctly predicted the location of the probe square on two thirds of the trials.
In other words, the cue indicated which location was most likely to be tested, making it worthwhile for this group of subjects to preferentially remember the memory array item presented at the cued location. Thus, we predicted that the subjects in this condition would be much more accurate when the cued location was probed (valid trials) than when an uncued location was probed (invalid trials).

For a second group of subjects, the cued location was no more and no less likely to be probed than any of the uncued locations. As a result, there was no particular reason for these subjects to preferentially remember the color of the square at the cued location, and any difference in accuracy between valid and invalid trials for these subjects would suggest that the cues automatically led to preferential memory storage.

\section{Method}

Subjects. Each group of subjects consisted of 12 college students, who participated for course credit or monetary compensation. All the subjects were between the ages of 18 and 30 years, reported normal or corrected-to-normal visual acuity, had normal color vision, and had no history of neurological problems.

Stimuli. The stimuli were presented on a VGA video monitor with a gray background $\left(2.2 \mathrm{~cd} / \mathrm{m}^{2}\right)$ and a continuously visible white fixation cross $\left(56 \mathrm{~cd} / \mathrm{m}^{2}\right)$. As is illustrated in Figure 1, the stimuli were presented at six locations that were evenly spaced around an imaginary circle with a radius of $4.7^{\circ}$ that was centered at fixation. Each memory array consisted of a $1^{\circ} \times 1^{\circ}$ filled square at each of the six locations. The color of each square was selected at random (without replacement) from a set of seven easily discriminable colors: brown $\left(x=.572, y=.381,12 \mathrm{~cd} / \mathrm{m}^{2}\right)$, red $(x=.636, y=.332$, $\left.21 \mathrm{~cd} / \mathrm{m}^{2}\right)$, blue $\left(x=.153, y=.068,8.81 \mathrm{~cd} / \mathrm{m}^{2}\right)$, green $(x=.319, y=$ $\left..567,59 \mathrm{~cd} / \mathrm{m}^{2}\right)$, off-white $\left(x=.316, y=.303,54 \mathrm{~cd} / \mathrm{m}^{2}\right)$, yellow $(x=$ $\left..474, y=.453,58 \mathrm{~cd} / \mathrm{m}^{2}\right)$, and violet $\left(x=.365, y=.149,6.3 \mathrm{~cd} / \mathrm{m}^{2}\right)$. The cue was a white $\left(55.94 \mathrm{~cd} / \mathrm{m}^{2}\right)$ outlined square, subtending $1.9^{\circ} \times$ $1.9^{\circ}$.

Procedure. Each trial began with a 500-msec presentation of a two-digit number at fixation that was used for the articulatory suppression task; the subjects were required to repeat this number aloud throughout the duration of the trial. The subjects were instructed to speak at a rate of 3-4 digits per second, and the experimenter continuously monitored the subjects to ensure adequate performance. After a 1,500-msec blank period, the cue box appeared for $50 \mathrm{msec}$ at one of the six locations, selected at random. This was followed by a $50-\mathrm{msec}$ blank period and a $100-\mathrm{msec}$ presentation of the memory array. After a 900-msec blank period, the probe square appeared for 2,000 msec. On half of the trials, the probe square was the same color as the memory array square that had previously been presented at the same location; on the remaining trials, the probe square was a different, randomly selected color. The subjects made an unspeeded manual response on a game pad, pressing with the index or middle finger of the preferred hand to indicate whether the color of the probe square matched the color of the corresponding memory array square. The next trial began 1,000 $\mathrm{msec}$ after the offset of the probe square.

For the subjects in the predictive-cue group, the probe square appeared at the cued location on two thirds of the trials and at a randomly selected uncued location on the remaining one third of the trials; for the subjects in the nonpredictive-cue group, the probe square appeared at the cued location on one sixth of the trials and at a randomly selected uncued location on the remaining five sixths of the trials. The subjects were informed of these probabilities. After a few minutes of practice with the task, each subject completed five blocks of 90 trials. 


\section{Results}

Figure 2 shows accuracy (percentage correct) for valid and invalid trials. The invalid trials were divided according to whether the probe square was presented at a location that was adjacent to the cued location (near-invalid) or was presented at one of the nonadjacentlocations ( farinvalid). For the predictive-cue subjects, accuracy was $30 \%-40 \%$ higher on valid trials than on invalid trials. In addition, performance on near-invalid trials was somewhat more accurate than performance on far-invalid trials. For the nonpredictive-cue subjects, accuracy was $15 \%-20 \%$ higher on valid trials than on invalid trials, and accuracy was again somewhat greater on near-invalid trials than on far-invalid trials.

The accuracy data were analyzed in a mixed-model analysis of variance (ANOVA), with a between-subjects factor of group (predictive or nonpredictive) and a withinsubjects factor of cue validity (valid, near-invalid, or farinvalid). This ANOVA yielded a significant main effect of cue validity $[F(2,44)=217.87, p<.001]$ and a significant interaction between cue validity and group $[F(2,44)=$ $30.56, p<.001]$. The main effect of group did not approach significance $(F<1)$. These statistics support the observation that the cue validity effect was greater for the predictive-cue group than for the nonpredictive-cuegroup.

Separate ANOVAs were also performed for each group separately, with a single factor of cue validity (valid, nearinvalid, or far-invalid). The cue validity effect was significant for both the predictive-cue and the nonpredictive-cue groups $[F(2,22)=214.49, p<.001$, and $F(2,22)=$ $41.17, p<.001$, respectively]. Planned comparisons between the valid and the near-invalid trials and between the near-invalid and the far-invalid trials were also conducted for both groups. In the predictive-cue group, there was a significant difference between the valid and the near-invalid trials $[F(1,11)=171.33, p<.001]$ and also a significant difference between the near-invalid and the far-invalid trials $[F(1,11)=12.46, p<.01]$. In the nonpredictive-cuegroup, the difference between the valid and the near-invalid trials was significant $[F(1,11)=38.48, p>.001]$, but the difference between the near-invalid and the far-invalid trials was only marginally significant $[F(1,11)=4.73, p<$ .06]. Thus, both predictive and nonpredictivecues yielded significant cue validity effects, with some evidence for greater accuracy at near-invalid than at far-invalid locations.

\section{Discussion}

These results indicate that spatial cues can influence visual working memory performance. Thus, spatial attention plays a role in controlling the transfer of perceptual information into visual working memory. Given that only 3-4 objects can be simultaneously maintained in visual working memory (Luck \& Vogel, 1997; Vogel et al., 2001) and that considerable time is required to transfer perceptual representations into visual working memory (Jolicœur $\&$ Dell'Acqua, 1998), it is sensible that attention should play this role. These results extend the findings of previous studies (e.g., Irwin \& Gordon, 1998; Palmer, 1988, 1990) by showing that cues effectively control visual working memory even when verbal recoding is prevented by means of the articulatory suppression procedure.

These results also indicate that peripheral luminance transients can bias the transfer of information into working memory even if they are nonpredictive, indicating some

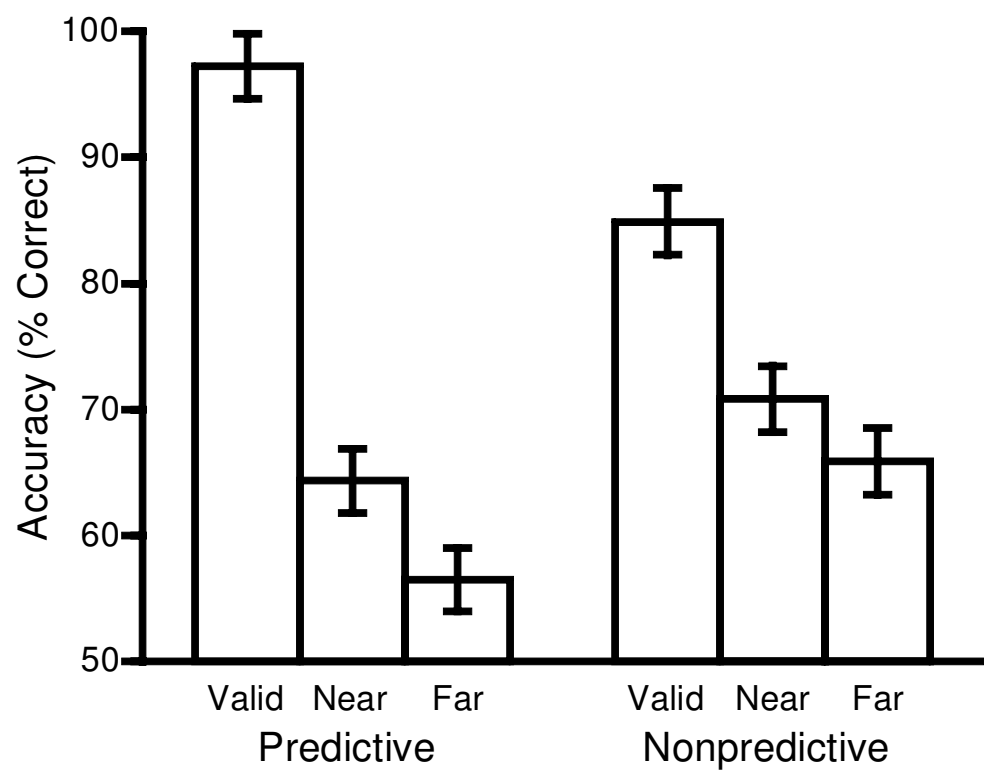

Figure 2. Accuracy (percentage correct) for valid, near-invalid, and farinvalid trials in the predictive and nonpredictive conditions of Experiment 1. Error bars show the $95 \%$ within-subjects confidence intervals (Loftus \& Loftus, 1988). 
degree of automaticity. The cue validity effect was smaller for nonpredictive cues than for predictive cues, which may indicate that attention is not captured as effectively by nonpredictive cues. Alternatively, attention may be drawn equally to predictive and nonpredictive cues, but it may dissipate by the time of the subsequent memory array unless held in place voluntarily. In other words, the effects of the cue may not have completely carried over to the memory array item that was subsequently presented at the location of the cue. This possibility was explored in Experiment 2 by means of the sudden-onset cuing paradigm developed by Yantis and his colleagues (Yantis \& Johnson, 1990; Yantis \& Jonides, 1984, 1990), in which the target itself serves as a cue.

\section{EXPERIMENT 2}

In Experiment 2, we examined the transfer of newly appearing objects into visual working memory by means of the sudden-onset paradigm developed by Yantis and Jonides (1984). As is illustrated in Figure 3, each trial of this experiment began with a set of gray placeholder squares. To create the memory array, these placeholder squares changed to different colors (these are called the no-onset objects), and a new colored square appeared at a previously blank location (this is called the onset object). If the appearance of a new object automatically captures attention and this variety of attention causes the attended object to be transferred into visual working memory, memory for the onset object should be better than memory for the no-onset objects. This should be true even if the onset object is no more likely to be probed than any of the no-onset objects.

\section{Method}

The stimuli and procedure were identical to those of Experiment 1, with a few exceptions. The subjects consisted of two new groups of 12 students drawn from the same population as that used in Experiment 1 .

The colored squares in the memory arrays were presented at a set of 12 locations evenly spaced around a circle with a radius of $4.7^{\circ}$ and centered on fixation (see Figure 3 ). At the beginning of each trial, gray placeholder squares $\left(2.2 \mathrm{~cd} / \mathrm{m}^{2}, 1^{\circ} \times 1^{\circ}\right)$ were presented for $2,000 \mathrm{msec}$ at 4 of the 12 locations. The placeholder array was followed immediately by the memory array, which contained five colored squares and was presented for $200 \mathrm{msec}$. Four of the five memory array squares occupied the same locations as the gray squares and thus served as the no-onset objects. The fifth square appeared at a previously empty location and served as the onset object. After an 800-msec blank delay period, a probe square appeared at a location that had previously contained a memory array square, and the subjects were required to report whether the probe matched the color of the preceding memory array item at that location.

In the predictive group, the onset object was probed on two thirds of the trials, and a randomly selected no-onset object was probed on one third of the trials. The subjects in this group were informed of the predictive nature of the onset item and were instructed to focus attention on this item. The subjects in the nonpredictive group were told that the onset and the no-onset items were equally likely to be probed and that they should not to pay any particular attention to the onset item. Owing to a programming error, the onset item was actually probed slightly less often $(17 \%)$ than each of the no-onset items $(21 \%)$ in this condition, but this should have further decreased any

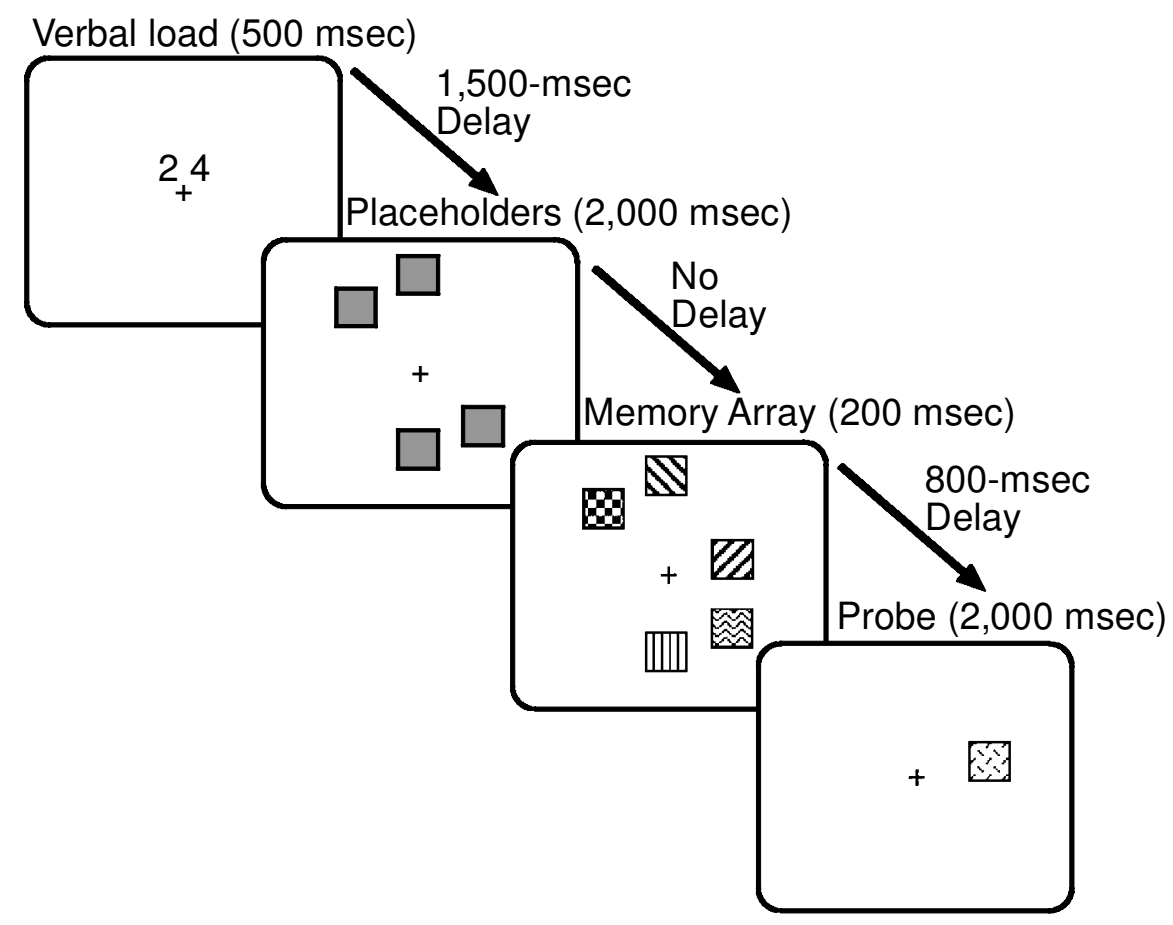

Figure 3. Example of the procedure used in Experiment 2. The stimuli are drawn much larger than they appeared on the actual video display, different fill patterns are used to represent different colors, and the verbal load and the fixation point were presented in white on a gray background. 
motivation to attend to the onset item. Each subject received a few minutes of practice at the beginning of the session, followed by six blocks of 72 trials.

Because the memory array in this experiment consisted of five squares distributed at random among 12 possible locations, it was not feasible to subdivide the no-onset trials as a function of the distance between the probed item and the onset item.

\section{Results and Discussion}

The results of this experiment are illustrated in Figure 4. In both the predictive and the nonpredictive groups, performance was substantially more accurate when the onset item was probed than when a no-onset item was probed. This led to a main effect of trial type in a two-way ANOVA, with factors of group and trial type $[F(1,22)=105.38, p<$ $.001]$. This effect was somewhat larger for the predictive group than for the nonpredictive group, leading to a significant interaction between group and trial type $[F(1,22)=$ $7.29, p<.02]$.

These results provide converging evidence that spatial attention can influence the storage of information in visual working memory. Moreover, they indicate that the onset of an object can automatically cause information about that object to be stored in visual working memory. As in Experiment 1 , the automatic attention effects in the nonpredictive group were not quite as strong as the combination of automatic and voluntary attention effects in the predictive group. Thus, sudden onsets do not completely capture attention in this context, even though they are quite effective.

\section{EXPERIMENT 3}

Before concluding that the difference between onset and no-onset trials in Experiment 2 reflects an effect of at- tention, it is necessary to rule out the possibility that onset items are simply more easily perceived or remembered than no-onset items, irrespective of attention. To rule out attention-independent explanations, we conducted a control experiment in which we separately tested memory performance for a set of onset items and for a set of no-onset items. On each trial, the memory array consisted of either five onset items or five no-onset items. If onset items have some kind of attention-independent advantage, memory performance should be more accurate for the onset arrays than for the no-onset arrays. In contrast, if the greater accuracy for onset items than for no-onset items in Experiment 2 was due solely to an automatic capture of attention, there should be no difference between onset and no-onset arrays in the present experiment.

\section{Method}

The stimuli and procedure were identical to those of Experiment 2, except as follows. A new group of 12 students was tested, drawn from the same population as that used in Experiments 1 and 2. Onset and no-onset arrays were randomly intermixed within blocks. Each memory array consisted of five items distributed at random among the 12 potential target locations. No-onset memory arrays were preceded by a 2,000-msec array of gray squares at the locations of the squares in the memory array. Onset memory arrays were preceded by a 2,000-msec blank interval. Each subject was administered a few minutes of practice and then three blocks of 60 trials each.

\section{Results and Discussion}

As is shown in Figure 5, accuracy was nearly identical for the onset and the no-onset arrays, with slightly better performance for the onset arrays. This slight difference did not approach significance in a one-way within-subjects ANOVA $(p>.3)$. Although it is impossible to prove that there is no difference between onset and no-onset arrays,

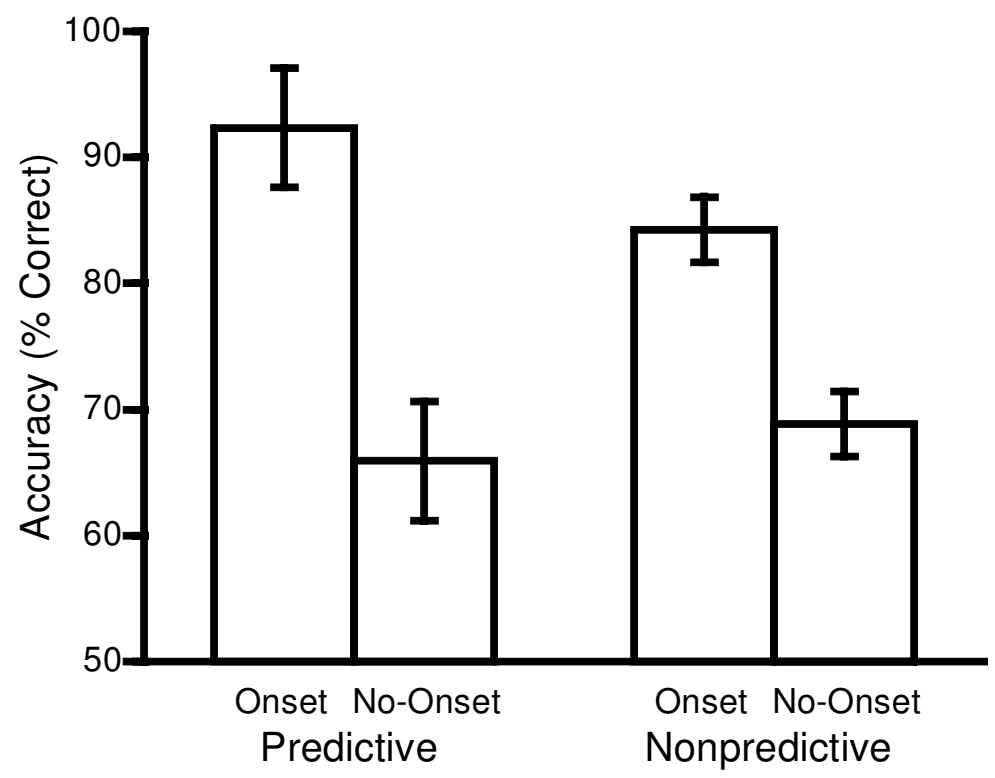

Figure 4. Accuracy (percentage correct) for the predictive and nonpredictive conditions of Experiment 2. Error bars show the $95 \%$ within-subjects confidence intervals. 
it is possible to show that any difference between them is very small. To accomplish this, we computed the difference between the onset and the no-onset conditions for each subject and then computed a $95 \%$ confidence interval for this difference score. The mean difference was $2.2 \%$, and the $95 \%$ confidence interval was $\pm 4.7 \%$; in other words, we have $95 \%$ confidence that the difference was between $-2.5 \%$ and $6.9 \%$. Such a small effect cannot explain the difference of more than $15 \%$ between onset and no-onset targets that was observed in Experiment 2. Thus, all or most of the difference between onset and noonset targets in Experiment 2 was due to the allocation of attention to the onset targets, rather than to an intrinsic difference in perceptibility or memorability between onset items and no-onset items.

\section{EXPERIMENT 4}

Although the preceding experiments suggest that attention can influence the transfer of perceptual representations into working memory, the effects could reflect an indirect effect of a perceptual modulation, rather than direct control over working memory. Specifically, even though the to-be-remembered stimuli were highly discriminable and performance presumably was not limited by the quality of the perceptual representations (see Vogel et al., 2001), the strength of the perceptual representation may have been increased at the attended location, and this may have indirectly biased the transfer of these items into working memory. To provide evidence against a perceptually mediated effect, the cues in Experiment 4 were presented after, rather than before, the memory arrays. It seems unlikely that a cue could improve the quality of the

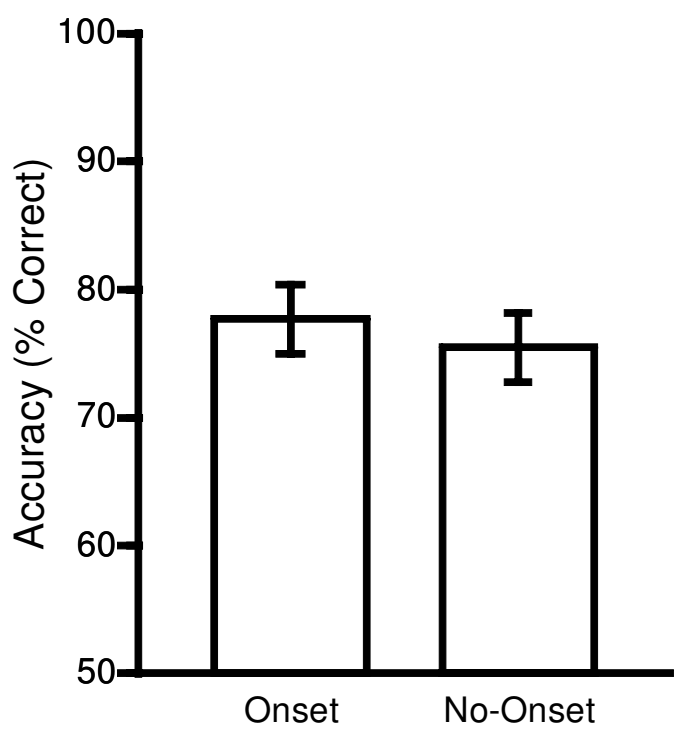

Figure 5. Accuracy (percentage correct) for the onset and noonset trials of Experiment 3. Error bars show the $95 \%$ withinsubjects confidence intervals. perceptual representation of a stimulus unless the cue appeared prior to the offset of the stimulus. However, a cue appearing after stimulus offset could easily influence the transfer of an existing perceptual representation into working memory; indeed, this is the logic behind the classic iconic memory experiments of Sperling (1960) and Averbach and Coriel (1961). Thus, if the cues in Experiment 1 influenced memory performance directly by controlling the transfer of perceptual representations into visual working memory, the cues should still be effective if they appear after the offset of the memory arrays. However, if the cues in Experiment 1 indirectly influenced memory by increasing the quality of the perceptual representations, the cues should be substantially less effective if presented after the memory array has disappeared.

\section{Method}

The stimuli and procedure were identical to those in Experiment 1, except as follows. Only the nonpredictive-cue condition was used. The cue stimulus followed the memory array, rather than preceding it. Specifically, the cue appeared for $50 \mathrm{msec}$ immediately after the offset of the memory array. The delay between the memory array offset and the probe onset remained at $900 \mathrm{msec}$.

\section{Results and Discussion}

As is shown in Figure 6, accuracy was 15\%-20\% greater on valid trials than on invalid trials, and accuracy was just slightly greater on near-invalid trials than on far-invalid trials. An ANOVA was conducted, with a single factor of cue validity (valid, near-invalid, or far-invalid), and the cue validity effect was highly significant $[F(2,22)=28.29$, $p<.001]$. Planned comparisons indicated that accuracy was significantly greater on valid trials than on nearinvalid trials $[F(1,11)=24.71, p<.001]$, and the slightly greater accuracy on near-invalid trials relative to farinvalid trials was also significant $[F(1,11)=6.05, p<.05]$.

The size of the validity effect in this experiment was almost exactly the same as that for the nonpredictive condition of Experiment 1 (see Figure 1). To compare the experiments statistically, the data from the present experiment and the data from the nonpredictive condition of Experiment 1 were entered into a two-way ANOVA, with a between-subjects factor of experiment and a within-subjects factor of cue validity. The main effect of cue validity was highly significant $[F(2,44)=65.42, p<.001]$, but neither the main effect of experiment nor the interaction between experiment and cue validity approached significance $(p \geq$ $.30)$.

These results indicate that nonpredictive peripheral cues are just as effective whether they appear just before or just after the memory array, which suggests that they directly influence the transfer of perceptual representations into working memory, rather than operating indirectly by influencing the quality of the perceptual representations. That is, it seems implausible that attention could improve the perceptual encoding of a stimulus after the stimulus has disappeared. ${ }^{1}$ However, it is still possible that attention may increase the relative strength of a perceptual repre- 


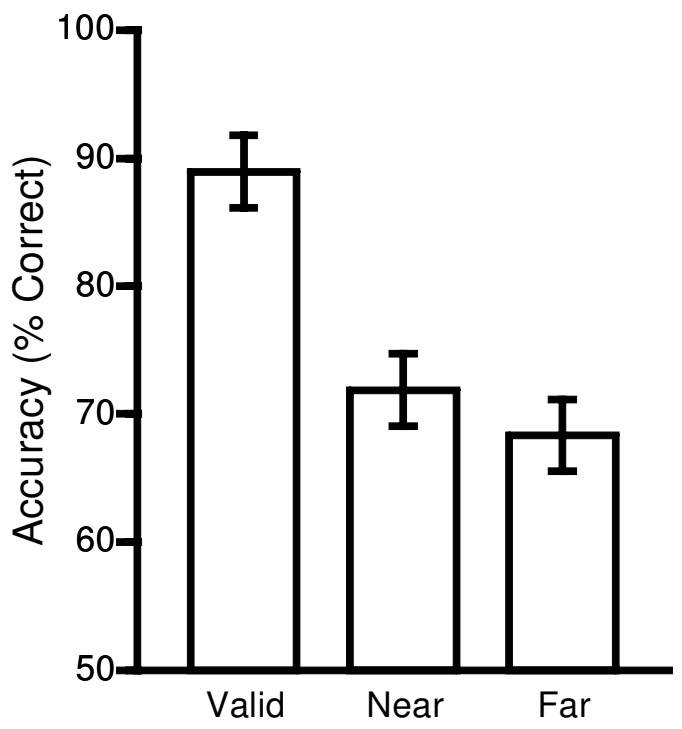

Figure 6. Accuracy (percentage correct) for valid, near-invalid, and far-invalid trials of Experiment 4 . Error bars show the $95 \%$ within-subjects confidence intervals.

sentation after stimulus offset, without actually improving the accuracy of the representation. This may, in turn, increase the probability that this representation is transferred into working memory. However, such a change in the relative strength of a representation should not be viewed as an effect of attention on perceptual encoding per se, because it does not improve the accuracy of the representation. Instead, changes in relative strength may simply be the mechanism by which the visual system controls the transfer of perceptual representations into working memory.

\section{GENERAL DISCUSSION}

These experiments provide evidence that focusing attention onto a spatial location, whether voluntarily or involuntarily, increases the probability that information at that location will be transferred into visual working memory. These results converge with previous studies (e.g., Irwin \& Gordon, 1998; Palmer, 1988, 1990; Scott-Brown $\&$ Orbach, 1998) to support the common assumption that attention can control the transfer of perceptual representations into visual working memory (e.g., Bundesen, 1990; Duncan \& Humphreys, 1989). Some theories go even further, proposing that visual working memory is the first stage of processing that is influenced by attention (e.g., Duncan \& Humphreys, 1989). However, this seems unlikely, given the neurophysiological evidence indicating that spatial attention can modulate the flow of sensory information through the visual system (Heinze et al., 1994; Luck, Chelazzi, Hillyard, \& Desimone, 1997; Luck et al., 1994). Nonetheless, attention may play an even more crucial role in working memory than in perception, because the bandwidth of visual perception appears to be many times greater than the bandwidth of visual working memory (Jolicœur \& Dell'Acqua, 1998; Potter, 1976; Thorpe, Fize, \& Marlot, 1996; Vogel, Luck, \& Shapiro, 1998).

The present experiments are the first to demonstrate that visual transients automatically influence the transfer of perceptual representations into working memory, just as they influence perceptual encoding. This finding has an obvious ecological explanation: Sudden changes in the visual input are likely to be the result of ecologically important events (e.g., the appearance of another animal), and should, therefore, receive priority for both perception and memory. However, several questions remain for future research. For example, the present finding that nonpredictive cues influence memory does not constitute evidence for strongly automatic orienting of attention. That is, we have not shown that the allocation of attention could not be overridden by the subjects' intentions. Although the subjects had no incentive to attend to the cued location, they also had little incentive not to attend to the cued location, so we do not know whether they could have voluntarily inhibited the orienting of attention to the cued location. In addition, it is possible that cued stimuli would not have been transferred into working memory if the subjects had not been performing a working memory task. Thus, although orienting to nonpredictive cues is generally regarded as evidence for some degree of automaticity, additional experiments are necessary to demonstrate strong automaticity (for an example of appropriate tests, see Jonides, 1981). In addition, although the results of Experiment 4 indicate that the present effects are not a result of an attention-related change in perceptual quality, the specific mechanism by which attention controls the transfer of perceptual representations into working memory remains to be determined.

When combined with previous studies (e.g., Cheal \& Gregory, 1997; Henderson, 1996; Henderson \& Macquistan, 1993; Luck \& Thomas, 1999), the present findings indicate that both predictive and nonpredictive cues can influence both perceptual encoding and the transfer of perceptual representations into visual working memory. This may indicate that a single attention system operates in both the perceptual and the working memory systems. In other words, a single system may be responsible for orienting attention in space, influencing the processing of stimuli at multiple stages of processing. Consistent with this idea, Pashler (1994) found that subjects could not easily make a perceptual discrimination about one set of stimuli while storing another set of stimuli in working memory, even though they could easily do both tasks on the same set of stimuli. In other words, it appeared as if subjects could not orient perceptual encoding to one set of stimuli while orienting working memory encoding to another set.

Contrary evidence was provided, however, by Woodman, Vogel, and Luck (2001), who found that subjects could conduct an attention-demanding visual search task just as easily when working memory was filled by a secondary 
task as they could when working memory was not filled. Moreover, the visual working memory task was not substantially impaired by the visual search task. The key difference between these studies may be that the subjects in the Pashler (1994) study were required to perform both perceptual and working memory encoding simultaneously, whereas the subjects in the Woodman et al. study performed perceptual encoding while maintaining previously encoded representationsin working memory. Thus, the Pashler study indicates that subjects cannot easily perform perceptual and working memory encoding simultaneously on different sets of objects, whereas the Woodman et al. study indicates that perceptual encoding may occur for one set of stimuli without obligatory working memory encoding of those stimuli. Taken together, these studies suggest that there is some linkage between the operation of attention in perception and in working memory, but the linkage is not complete.

\section{REFERENCES}

Averbach, E., \& Coriel, A. S. (1961). Short-term memory in vision. Bell System Technical Journal, 40, 309-328.

BAdDEley, A. D. (1986). Working memory. Oxford: Oxford University Press, Clarendon Press.

Besner, D., Davies, J., \& Daniels, S. (1981). Reading for meaning: The effects of concurrent articulation. Quarterly Journal of Experimental Psychology, 33A, 415-437.

Bundesen, C. (1990). A theory of visual attention. Psychological Review, 97, 523-547.

Cheal, M., \& Gregory, M. (1997). Evidence of limited capacity and noise reduction with single-element displays in the location-cuing paradigm. Journal of Experimental Psychology: Human Perception \& Performance, 23, 51-71.

Duncan, J., \& Humphreys, G. (1989). Visual search and stimulus similarity. Psychological Review, 96, 433-458.

Estes, W. K. (1973). Phonemic coding and rehearsal in short-term memory for letter strings. Journal of Verbal Learning \& Verbal Behavior, 12, 360-372.

Folk, C. L., \& Remington, R. (1999). Can new objects override attentional control settings? Perception \& Psychophysics, 61, 727-739.

Folk, C. L., Remington, R. W., \& Johnston, J. C. (1992). Involuntary covert orienting is contingent on attentional control settings. Journal of Experimental Psychology: Human Perception \& Performance, 18, 1030-1044.

Folk, C. L., Remington, R. W., \& Johnston, J. C. (1993). Contingent attentional capture: A reply to Yantis (1993). Journal of Experimental Psychology: Human Perception \& Performance, 19, 682-685.

Folk, C. L., Remington, R. W., \& Wright, J. H. (1994). The structure of attentional control: Contingent attentional capture by apparent motion, abrupt onset, and color. Journal of Experimental Psychology: Human Perception \& Performance, 20, 317-329.

Gegenfurtner, K. R., \& Sperling, G. (1993). Information transfer in iconic memory experiments. Journal of Experimental Psychology: Human Perception \& Performance, 19, 845-866.

Heinze, H. J., Mangun, G. R., Burchert, W., Hinrichs, H., Scholz, M., Münte, T. F., Gös, A., Scherg, M., Johannes, S., Hundeshagen, H., Gazzaniga, M. S., \& Hillyard, S. A. (1994). Combined spatial and temporal imaging of brain activity during visual selective attention in humans. Nature, 372, 543-546.

Henderson, J. M. (1996). Spatial precues affect target discrimination in the absence of visual noise. Journal of Experimental Psychology: Human Perception \& Performance, 22, 780-787.

Henderson, J. M., \& Macquistan, A. D. (1993). The spatial distribution of attention following an exogenous cue. Perception \& Psychophysics, 53, 221-230.
Hopfinger, J. B., \& MANGun, G. R. (1998). Reflective attention modulates processing of visual stimuli in human extrastriate cortex. Psychological Science, 9, 441-447.

IrwIN, D. E. \& Gordon, R. D. (1998). Eye movements, attention and trans-saccadic memory. Visual Cognition, 5, 127-155.

Jolicceur, P., \& Dell'Acqua, R (1998). The demonstration of short-term consolidation. Cognitive Psychology, 36, 138-202.

JoNIDES, J. (1981). Voluntary versus automatic control over the mind's eye's movement. In J. [B.] Long \& A. [D.] Baddeley (Eds.), Attention and performance IX (pp. 187-203). Hillsdale, NJ: Erlbaum.

LapPin, J. S., \& UtTaL, W. R. (1976). Does prior knowledge facilitate the detection of visual targets in random noise? Perception \& Psychophysics, 20, 367-374.

LEVY, B. A. (1971). Role of articulation in auditory and visual shortterm memory. Journal of Verbal Learning \& Verbal Behavior, 10, 123-132.

Loftus, G. R, \& Loftus, E. F. (1988). Essence of statistics (2nd ed.). New York: Random House.

LogIE, R. H. (1995). Visuo-spatialworking memory. Hove, U.K.: Erlbaum.

Luck, S. J., Chelazzi, L., Hillyard, S. A., \& Desimone, R. (1997). Neural mechanisms of spatial selective attention in areas V1, V2, and V4 of macaque visual cortex. Journal of Neurophysiology, 77, 2442.

Luck, S. J., Hillyard, S. A., Mouloua, M., \& Hawkins, H. L. (1996). Mechanisms of visual-spatial attention: Resource allocation or uncertainty reduction? Journal of Experimental Psychology: Human Perception \& Performance, 22, 725-737.

Luck, S. J., Hillyard, S. A., Mouloua, M., Woldorff, M. G., Clark, V. P., \& Hawkins, H. L. (1994). Effects of spatial cuing on luminance detectability: Psychophysical and electrophysiological evidence for early selection. Journal of Experimental Psychology: Human Perception \& Performance, 20, 887-904.

Luck, S. J., \& Thомas, S. J. (1999). What variety of attention is automatically captured by peripheral cues? Perception \& Psychophysics, 61, 1424-1435.

LucK, S. J., \& Vogel, E. K. (1997). The capacity of visual working memory for features and conjunctions. Nature, 390, 279-281.

Murray, D. J. (1967). The role of speech responses in short-term memory. Canadian Journal of Psychology, 21, 263-276.

Palmer, J. (1988). Very short-term visual memory for size and shape. Perception \& Psychophysics, 43, 278-286.

Palmer, J. (1990). Attentional limits on the perception and memory of visual information. Journal of Experimental Psychology: Human Perception \& Performance, 16, 332-350.

Palmer, J., \& Ames, C. T. (1992). Measuring the effect of multiple eye fixations on memory for visual attributes. Perception \& Psychophysics, 52, 295-306.

PASHler, H. (1994). Divided attention: Storing and classifying briefly presented objects. Psychonomic Bulletin \& Review, 1, 115-118.

PoSNer, M. I. (1980). Orienting of attention. Quarterly Journal of Experimental Psychology, 32, 3-25.

PosNer, M. I., \& CoHEN, Y. (1984). Components of visual orienting. In H. Bouma \& D. G. Bouwhuis (Eds.), Attention and performance $X$ : Control of language processes (pp. 531-556). Hillsdale, NJ: Erlbaum.

PotTER, M. C. (1976). Short-term conceptual memory for pictures. Journal of Experimental Psychology: Human Learning \& Memory, 2, 509-522.

Prinzmetal, W., Presti, D. E., \& Posner, M. I. (1986). Does attention affect visual feature integration? Journal of Experimental Psychology: Human Perception \& Performance, 12, 361-369.

ScotT-Brown, K. C., \& Orbach, H. S. (1998). Contrast discrimination, non-uniform patterns and change blindness. Proceedings of the Royal Society of London: Series B, 265, 2159-2166.

ShiU, L., \& PASHLER, H. (1994). Negligible effect of spatial precuing on identification of single digits. Journal of Experimental Psychology: Human Perception \& Performance, 20, 1037-1054.

SPERLING, G. (1960). The information available in brief visual presentations. Psychological Monographs, 74 (11, Whole No. 498), 29.

Theeuwes, J., Kramer, A. F., \& Atchley, P. (1999). Attentional effects on preattentive vision: Spatial precues affect the detection of 
simple features. Journal of Experimental Psychology: Human Perception \& Performance, 25, 341-347.

Thorpe, S., Fize, D., \& Marlot, C. (1996). Speed of processing in the human visual system. Nature, 381, 520-522.

Vogel, E. K., LucK, S. J., \& ShaPIRo, K. L. (1998). Electrophysiological evidence for a postperceptual locus of suppression during the attentional blink. Journal of Experimental Psychology: Human Perception \& Performance, 24, 1656-1674.

Vogel, E. K., Woodman, G. F., \& Luck, S. J. (2001). Storage of features, conjunctions, and objects in visual working memory. Journal of Experimental Psychology: Human Perception \& Performance, 27, 92-114.

Woodman, G. F., Vogel, E. K., \& LucK, S. J. (2001). Visual search remains efficient when visual working memory is full. Psychological Science, 12, 219-224.

YANTIS, S. (1993). Stimulus-driven attentional capture and attentional control settings. Journal of Experimental Psychology: Human Perception \& Performance, 19, 676-681.

YANTIS, S. (1996). Attentional capture in vision. In A. F. Kramer, M. G. H. Coles, \& G. D. Logan (Eds.), Converging operations in the study of selective attention (pp. 45-76). Washington, DC: American Psychological Association.

YANTIS, S., \& JoHnSON, J. (1990). Mechanisms of attentional priority. Journal of Experimental Psychology: Human Perception \& Performance, 16, 812-825.

YANTIS, S., \& JonidES, J. (1984). Abrupt visual onsets and selective at- tention: Evidence from visual search. Journal of Experimental Psychology: Human Perception \& Performance, 10, 601-621.

YANTIS, S., \& Jonides, J. (1990). Abrupt visual onsets and selective attention: Voluntary versus automatic allocation. Journal of Experimental Psychology: Human Perception \& Performance, 16, 121-134.

\section{NOTES}

1. There is one way in which attention could conceivably influence perceptual encoding even though the cue appeared after the offset of the memory array. Specifically, the cue may be detected by a relatively fast visual pathway (i.e., the magnocellular pathway), and the colors of the memory array items may be encoded by a relatively slow visual pathway (i.e., the parvocellular pathway). In this manner, the cue information might arrive in the visual cortex before the color information, providing an opportunity for attention to modulate the perceptual encoding of the color information. However, previous evidence suggests that a peripheral cue must precede a target by at least $200 \mathrm{msec}$ to influence the accuracy of perceptual encoding (Luck, Hillyard, Mouloua, \& Hawkins, 1996). Thus, if the present cue validity effects were due solely to changes in perceptual encoding, they should have been substantially smaller when the cue appeared after, rather than before, the memory array.

(Manuscript received June 26, 2000;

revision accepted for publication November 5, 2001.) 